\title{
Meta-analysis of health state utility values measured by EuroQol 5-dimensions (EQ5D) questionnaire in Chinese women with breast
} cancer

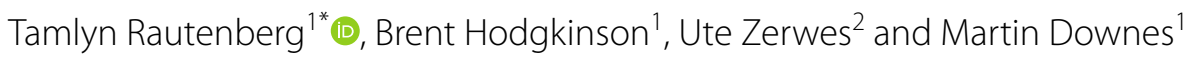

\begin{abstract}
Background: To synthesise EQ5D health state utility values in Chinese women with breast cancer for parameterising a cost utility model.

Methods: Eligible studies had to report health state utility values measured by EQ-5D in Chinese women diagnosed with breast cancer. Risk of bias was assessed using the Newcastle Ottawa Scale (NOS). Data from single arm studies was pooled using meta-analysis of single proportions to provide overall point estimates and $95 \%$ confidence intervals for fixed and random effects models using the inverse variance and Der Simonian-Laird methods respectively. Heterogeneity was evaluated using the $\mathrm{I}^{2}$ statistic and sensitivity analysis and meta-regression were conducted.

Results: Five papers were included, when all studies were combined $(n=4,100)$ the mean utility $(95 \%$ confidence interval) for random effects model was $0.83(0.78,0.89)$; for TNM 0-1 $0.85(0.75,0.95)$; for TNM II $0.85(0.78,0.93)$; for TNM III $0.83(0.77,0.90)$ and for TNM IV $0.73(0.63,0.82)$. The utility of patients in State P (first year after primary breast cancer) $0.84(0.80,0.88)$; in State R (first year after recurrence) $0.73(0.69,0.76)$, in State $S$ (second and following years after primary breast cancer or recurrence) $0.88(0.83,0.92)$; and in State $\mathrm{M}$ (metastatic disease) $0.78(0.74,0.82)$. Mean utility for duration since diagnosis 13 to 36 months was $0.88\left(0.80,0.96, I^{2}=95 \%\right)$; for 37 to 60 months $0.89\left(0.82,0.96, I^{2}=90 \%\right)$; for more than 60 months $0.86\left(0.76,0.96, I^{2}=90 \%\right)$. Mean utility for chemotherapy was $0.86\left(0.79,0.92,1^{2}=97 \%\right)$; for radiotherapy $0.83\left(0.69,0.96, \mathrm{I}^{2}=97 \%\right)$; surgery $0.80\left(0.69,0.91, \mathrm{I}^{2}=98 \%\right)$; concurrent chemo-radiation $0.70(0.60,0.81$, $\left.\mathrm{I}^{2}=86 \%\right)$ and endocrine therapy $0.90\left(0.83,0.97, \mathrm{I}^{2}=91 \%\right)$. Conclusion: This study synthesises the evidence for health state utility values for Chinese women with breast cancer which is useful to inform cost utility models.
\end{abstract}

Keywords: evidence synthesis, meta-analysis, health state utility value, EQ-5D, breast cancer, China

\section{Background}

Breast cancer has now overtaken lung cancer to become the most commonly diagnosed cancer in women in China [1, 2]. The number of breast cancer cases in China increased from 304,000 in 2015 to 413,000 in

\footnotetext{
*Correspondence: t.rautenberg@griffith.edu.au

${ }^{1}$ Centre for Applied Health Economics, Griffith University, Brisbane, Australia

Full list of author information is available at the end of the article
}

$2020[2,3]$. Breast cancer impacts on physical and emotional wellbeing which, taken together, provide an indication of patient's quality of life. Quality of life is an important indicator of the impact of health status on patients' wellbeing. It is usually an important component of measuring patients' health outcomes and can be used to inform decision making.

This is particularly relevant now, as pharmacoeconomics is playing an increasingly important role in China, evidenced by the recent 2020 guideline 
that recommends cost-utility analysis and quality adjusted life years for pharmacoeconomic analysis $[4,5]$. It also advocates indirect measures like the five-level EuroQoL Group's five-dimension questionnaire (EQ-5D) using the scoring algorithm for Chinese population, over direct measures [4]. The EQ-5D is a widely used and internationally validated instrument measuring utility on a scale between zero (death) and one (full health). Respondents value their own health against five domains (mobility, self-care, usual activity, pain/discomfort and anxiety/depression) and grade their response according to three $(3 \mathrm{~L})$ or, more recently, five $(5 \mathrm{~L})$ levels of each domain. Values are converted to utilities using a reference population's value set. A valuation set is available for China and studies confirm that the Chinese version provides comparable results to the English version [6, 7]. Importantly, the EQ-5D has demonstrated validity, responsiveness, and reliability in assessing health outcomes specifically for breast cancer patients $[8,9]$.

Cost utility analyses require health state utility values. There are few studies that measure health state utility values of Chinese women with breast cancer and these few studies, when taken together may provide an estimate of effect which can be useful to inform decisions making. To parameterise a cost utility model when multiple primary studies are available, performing an evidence synthesis with a single arm pooling (or meta-analysis), can provide an acceptable estimate and is in keeping with best practice recommendations for modelling [10]. In the context of the burden of breast cancer in China, the increasing role of Pharmacoeconomics and the need to parameterise a cost-utility model, the following meta-analysis was undertaken.

\section{Methods}

Literature search strategy: Pubmed (Medline, Pubmed central and Bookshelf) was searched (28.05.2020) from January 2002 to May 2020. The Cochrane and Centre for Reviews and Dissemination databases were searched (Cochrane Database of Systematic Reviews, Database of Abstracts of Reviews of Effectiveness (DARE), Cochrane Central Register of Clinical Trials, Health Technology Assessment (HTA), Economic Evaluation (NHS EED) was searched on (20.11.2020). The literature search strategy was replicated on 20.08.2021 for the preceding year, no new results were identified. Citation snowballing was used to identify additional papers. The search terms in Table 1 were combined using Boolean operators.

Eligibility criteria: pre-specified selection criteria were applied. Included studies had to be conducted in China (or Asian countries with $>80 \%$ Chinese participants), had to use the EQ5D instrument to measure Quality of Life and had to report health state utility values of women with breast cancer. Included studies needed to report essential summary measures required for meta-analysis (mean utility and variance).

Study selection: Titles and abstracts were screened by two trained, independent reviewers (TR, BH). Titles/ abstracts of unclear eligibility were included at this stage. Full texts were retrieved and reviewed by two independent reviewers (TR, BH). Discrepancies were resolved via an independent third reviewer (MD).

Data extraction and quality assessment: Data was extracted and verified independently by two reviewers (UZ, BH). Data fields extracted included study location and design, population demographics, the description of the related health state, sample size, mean utility and variance. Risk of bias was assessed using the Newcastle Ottawa Scale (NOS) which is applicable for assessing the level of bias in single-arm non-randomized studies [11]. The NOS scale is comprised of five items addressing

Table 1 Search terms used (all databases)

\begin{tabular}{ll}
\hline Element of clinical question & Search terms \\
\hline Population Mesh terms Humans, Women, Quality of life, Quality Adjusted & Breast neoplasm*(TI/AB), Breast cancer* (TI/AB), Breast carcinoma* (TI/AB), \\
Life Years, Breast neoplasms & Breast tumour* (TI/AB), Mammary cancer* (TI/AB), Mammary neoplasm* \\
& (TI/AB),Mammary carcinoma* (TI/AB), Mammary tumor* (TI/AB) China (TI/ \\
& AB), Chinese (TI/AB) \\
Intervention/ comparator/outcome(s) & EuroQoL, EuroQoL-5D, EQ-5D, \\
& Health utilities [tw], Health-state utilities [tw] \\
& Health Utilities Index [tw], HUI2, HUI3, \\
& Utility score [tw], Utility value* [tw], \\
& Utilities [tw] NOT (clinical utilities [tw] OR Diagnostic utilities [tw]), \\
& Utility [tw] NOT (clinical utility [tw] OR diagnostic utility [tw]), \\
& Standard gamble [tw], \\
& Time trade-off [tw], TTO [tiab]
\end{tabular}




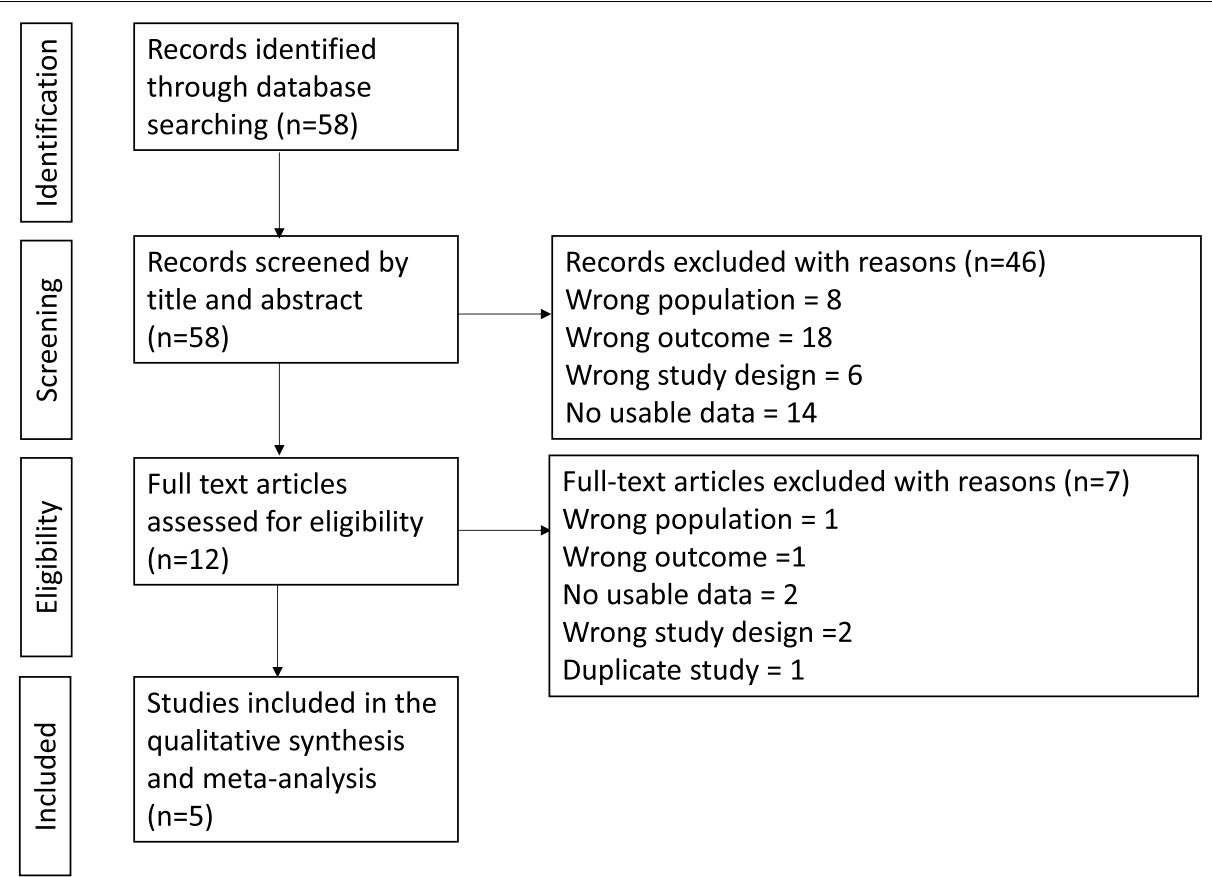

Fig. 1 PRISMA diagram describing the results of the literature search and the reasons for study exclusion

subject selection and attrition, reporting all intended outcomes, and any other relevant considerations, rating each item as either at low, unclear or high risk of bias [11]. NOS has been applied to other single arm studies including a systematic review by the Agency for Healthcare Research and Quality and a review of chloroquine/ hydroxychloroquine effectiveness for COVID-19 [12, 13]. The literature review was conducted and reported in compliance with Cochrane and PRISMA guidelines [14, 15].

Meta-analysis: The meta-analysis was considered feasible if two or more studies reported utility for breast cancer and was conducted according to international recommendations [16]. Data from the single arm studies were pooled and meta-analysis of single proportions (metaprop) was conducted from the $\mathrm{R}$ meta package (version 3.6.1) to provide point estimates and 95\% confidence intervals (CI) for fixed and random effects models (using the inverse variance method and Der Simonian-Laird method respectively) [17]. Heterogeneity was evaluated using the $\mathrm{I}^{2}$ statistic and where possible meta-regression of covariates was conducted in OpenMeta [18]. Meta-analysis was performed for all patients, according to Tumor Nodal Metastases (TNM) staging system and PRSM states. State P was defined as first year after diagnosis of primary breast cancer; State R as first year after recurrence; State $\mathrm{S}$ as second and following years after primary breast cancer/recurrence; State $M$ as metastatic breast cancer.

\section{Results}

Study selection: A total of 58 papers were identified and 53 of which were excluded during title/abstract screening and full text assessment. In total, nine papers were excluded because they focused on incorrect population (conducted outside China/did not include more than $80 \%$ of Chinese respondents/focus on other cancers). Nineteen studies did not report quality of life data or derived it according to other disease-specific or generic instruments. Sixteen studies did not report sufficient measures of effect and variance and had no usable data. Eight studies were the incorrect study design, six of which were economic evaluations/cost effectiveness studies and two of which were pilot studies. One duplicate study was identified which reports the same patient sample (personal communication) and values, the most recent paper has been included in the analysis [19,20]. Five studies met the eligibility criteria [20-24]. A PRISMA flow diagram is shown in Fig 1.

Study overview: Four of the five studies were full published papers [20,21,23,24] and one was in poster format and provided all data required [22]. Yang (2020) performed a survey of 446 patients in a tertiary oncology hospital in China between November 2017 and May 2018 [20]. Li et al (2019) measured utility in a sample of 608 
breast cancer patients who underwent inpatient treatment at a single hospital in China between October 2014 to February 2015 [23]. Ou (2019) measured utility in a cross-sectional survey of 193 Chinese patients in Taiwan in 2017 [24]. Wang (2018) reported on utility scores from a survey of 2,626 breast cancer patients across 12 provinces in China from September 2013 to December 2014 [22]. The oldest study by Cheung (2014) was a crosssectional survey in two cancer centres in Singapore of a sample of 238 Asian inpatients and outpatients with histologically confirmed breast cancer in 2014 [21]. Wang used the three-level version of the EQ5D, all other studies used the five-level version. Cheung (2014) used a Japanese value set as the study was conducted prior to the publication of a Chinese data set [21]. A summary of key differences is shown in Table 2.

Quality assessment: With respect to sampling bias: $\mathrm{Ou}$ is considered to be at high risk of being non-representative of the general population because it includes patients referred to a specialist clinic with hormone receptor positive and human epidermal growth factor receptor 2 negative subtypes of breast cancer only. Furthermore, although the study includes $100 \%$ Chinese patients, it is conducted in Taiwan. Cheung is considered to be at moderate risk of bias because it includes $81 \%$ of Chinese patients from Singapore [21, 24]..

Four of the studies were judged to be at low risk of attrition bias: Wang did not report the number of participants that utility values were elicited from and $\mathrm{Ou}$ [22] neglected to account for dropouts (5.7\% of initial study population )[24]. In the Cheung study, 280 patients consented to the study, 39 did not self-administer the questionnaire and 3 patients were excluded due to missing values in two measuring instruments beyond imputation by the half rule [21]. In the Li study, 621 patients were interviewed, 11 did not complete the questionnaire, 1 did not answer a TTO question, 1 did not complete the clinical chart leaving a sample of 608 participants and 1 other participant with missing values [23]. Yang was considered to be at moderate risk of bias because it did not report information on attrition.

Four of the studies were considered at low risk of bias with respect to timing of administering the EQ5D. $\mathrm{Li}$ and Yang had similar distribution of patients according to time since diagnosis. Approximately a third were less than 12 months since diagnosis ( $31 \%$ vs. $31 \%)$; a third were $13-36$ months since diagnosis (32\% vs $33 \%$ ); remainder of patients were distributed evenly across 37 to 60 months (19\% vs $17 \%)$ and more than 61 months since diagnosis ( $18 \%$ vs $20 \%$ ) for $\mathrm{Li}$ and Yang respectively. Ou study was considered to be at moderate risk of bias because more patients were longer since diagnosis compared to Li and Yang: 34\% of patients were within 36 months of diagnosis, $39 \%$ were $37-60$ months, $14 \%$ were 84-108 months and $13 \%$ were more than 108 months since diagnosis. According to Wang, 9\% of respondents were pre-treatment, $64 \%$ were having treatment, $21 \%$ were after treatment and $6 \%$ were during follow-up. Cheung did not explicitly state duration, however $48 \%$ were undergoing treatment, 33\% were having palliative treatment and $19 \%$ were having follow-up or no treatment. Both studies were considered to be low risk of bias. No issues of selective reporting were raised, except for Yang due to the failure to report details on attrition. The risk of bias assessed by NOS is shown in Table 3 .

Study characteristics: The average age of study participants ranged between 48 and 55 years, with the majority of participants being married (range $71 \%$ to $92 \%$ ). Participants from Taiwan [24] and Singapore [21] were more highly educated ( $42 \%$ and $33 \%$ respectively) than participants recruited in China (14\%-25\%) [20, 23].

Health state utility values: Utility values from the five included studies are shown in Table 4.

Meta-analysis: When mean utility from all patients in the five studies are combined $(\mathrm{n}=4,100)$ the mean utility $(95 \%$ confidence interval) is $0.83(0.78,0.89)$ and 0.82 $\left(0.81,0.83, \mathrm{I}^{2}=99 \%\right)$ for random and fixed effects models respectively shown in Table 5 .

Table 2 Key differences in studies

\begin{tabular}{|c|c|c|c|c|c|}
\hline Study & Region & Year of the data & Sample size & Levels of EQ-5D & Value set \\
\hline Li [23] & China & October 2014 to February 2015 & 608 & Five & $\begin{array}{l}\text { Chinese } 5 \mathrm{~L} \text { value set Luo } 2017 \text { - } \\
\text { Time trade off (TTO) }\end{array}$ \\
\hline Ou [24] & Taiwan (100\% Chinese) & $\begin{array}{l}2017 \text { (specific time period not } \\
\text { stated) }\end{array}$ & 193 & Five & $\begin{array}{l}\text { Chinese } 5 \mathrm{~L} \text { value set Luo } 2017 \text { - } \\
\text { Time trade off (TTO) }\end{array}$ \\
\hline Wang [22] & China & $\begin{array}{l}\text { September } 2013 \text { to December } \\
2014\end{array}$ & 2626 & Three & $\begin{array}{l}\text { Chinese } 3 \mathrm{~L} \text { value set Liu } 2014 \text { - - } \\
\text { Time trade off (TTO) }\end{array}$ \\
\hline Cheung [21] & Singapore ( $81 \%$ Chinese) & $\begin{array}{l}\text { Prior to } 2013 \text { (specific time period } \\
\text { not stated [7]) }\end{array}$ & 238 & Five & $\begin{array}{l}\text { Japanese value set (only available } \\
\text { Asian value set for the cross-walk } \\
\text { project at that time). }\end{array}$ \\
\hline Yang [20] & China & November 2017 to May 2018. & 446 & Five & $\begin{array}{l}\text { Chinese } 5 \mathrm{~L} \text { value set Luo } 2017 \text { - } \\
\text { Time trade off (TTO) }\end{array}$ \\
\hline
\end{tabular}


Table 3 Newcastle Ottawa Scale Risk of Bias Ratings

\begin{tabular}{|c|c|c|c|c|c|}
\hline \multirow[t]{2}{*}{ Newcastle Ottawa Scale Question } & \multicolumn{5}{|l|}{ First author, year } \\
\hline & Cheung 2014 [21] & Wang 2018 [22] & $\begin{array}{l}\mathrm{Li} \\
2019[23]\end{array}$ & $\begin{array}{l}\text { Ou } \\
2019[24]\end{array}$ & Yang 2020 \\
\hline $\begin{array}{l}\text { Sampling: Were the subjects in the study representative of the } \\
\text { entire population from which they were recruited? }\end{array}$ & Moderate & Low & Low & High & Low \\
\hline $\begin{array}{l}\text { Measurement: Incomplete outcome data: attrition bias due to } \\
\text { amount, nature or handling of incomplete outcome data }\end{array}$ & Low & Low & Low & Low & Moderate \\
\hline $\begin{array}{l}\text { Measurement: Do the analyses adjust for different lengths of follow- } \\
\text { up of patients? }\end{array}$ & Low & Low & Low & Moderate & Low \\
\hline $\begin{array}{l}\text { Measurement: Selective reporting: reporting bias due to selective } \\
\text { outcome reporting }\end{array}$ & Low & Low & Low & Low & Moderate \\
\hline Additional bias: Bias due to problems not covered elsewhere. & Low & Low & Low & Low & Low \\
\hline
\end{tabular}

The Newcastle-Ottawa Scale (NOS) [11].

When studies were combined according to TNM stage, for TNM $0-1$ and $1(\mathrm{n}=721)$ mean utility was 0.85 $(0.75,0.95)$ and $0.85\left(0.84,0.86, \mathrm{I}^{2}=98 \%\right)$; for TNM II $(\mathrm{n}=1,441) 0.85(0.78,0.93)$ and $0.81\left(0.80,0.82, \mathrm{I}^{2}=97 \%\right)$; for TNM III $(\mathrm{n}=811) 0.83(0.77,0.90)$ and $0.80(0.79,0.81$, $\left.\mathrm{I}^{2}=95 \%\right)$ and TNM IV $(\mathrm{n}=297) 0.73(0.63,0.82)$ and 0.71 $\left(0.68,0.73, \mathrm{I}^{2}=89 \%\right)$ for random and fixed effects models respectively shown in Table 6 .

$\mathrm{Li}$ and Yang reported data by cancer state, mean utility for state $\mathrm{P}(\mathrm{n}=282)$ was $0.84(0.80,0.88)$ and $0.85(0.82$, $\left.0.87, \mathrm{I}^{2}=71 \%\right)$; for state $\mathrm{S}(\mathrm{n}=503) 0.88(0.83,0.92)$ and $0.88\left(0.87,0.89, \mathrm{I}^{2}=97 \%\right)$; for state $\mathrm{R}(\mathrm{n}=85) 0.73(0.69$, $0.76)$ and $0.73\left(0.69,0.76, \mathrm{I}^{2}=0 \%\right)$; for state $\mathrm{M}(\mathrm{n}=184)$ $0.78(0.74,0.82)$ and $0.78\left(0.75,0.82, \mathrm{I}^{2}=17 \%\right)$ for random and fixed effects models respectively shown in Table 7.

$\mathrm{Li}$ and Yang reported data according to time since diagnosis. Mean utility for duration 13 to 36 months $(\mathrm{n}=263)$ was $0.88(0.80,0.96)$ and $0.89\left(0.88,0.91, \mathrm{I}^{2}=95 \%\right)$; for 37 to 60 months $(\mathrm{n}=186) 0.89(0.82,0.96)$ and 0.90 $\left(0.89,0.92, \mathrm{I}^{2}=90 \%\right)$; for more than 60 months $(\mathrm{n}=161)$ $0.86(0.76,0.96)$ and $0.84\left(0.81,0.85, \mathrm{I}^{2}=90 \%\right)$ for random and fixed effects models respectively shown in Table 8.

$\mathrm{Li}, \mathrm{Ou}$ and Wang reported data according to treatment regimen. Mean utility for chemotherapy $(\mathrm{n}=850)$ was $0.86(0.79,0.92)$ and $0.85\left(0.84,0.86, \mathrm{I}^{2}=97 \%\right)$; for radiotherapy $(\mathrm{n}=332) 0.83(0.69,0.96)$ and $0.90\left(0.88,0.91, \mathrm{I}^{2}\right.$ $=97 \%)$ and for surgery $(\mathrm{n}=891) 0.80(0.69,0.91)$ and 0.77 $\left(0.76,0.79, \mathrm{I}^{2}=98 \%\right)$. Li and Wang reported concurrent chemo-radiation therapy $(\mathrm{n}=73) 0.70(0.60,0.81)$ and $0.70\left(0.66,0.74, \mathrm{I}^{2}=86 \%\right) \mathrm{Li}$ and $\mathrm{Ou}$ reported results for endocrine therapy $(n=180) 0.90(0.83,0.97)$ and 0.92 $\left(0.91,0.93, \mathrm{I}^{2}=91 \%\right)$ for random and fixed effects models respectively shown in Table 9.

Meta-regression: Results for the meta-regression (Table 10) are limited to analyses that included three or more studies and was not possible according to breast cancer state [20, 23]. Adding Cheung (Singapore) decreased utility by $0.05(\mathrm{p}=0.14)$ and adding Ou (Taiwan) increased utility by $0.10(\mathrm{p}<0.001)$.
Using the EQ5D five level version increased utility by $0.85(\mathrm{p}<0.001)$ and three level version decreased it by $0.07(\mathrm{p}=0.193)$. Using the Chinese three level value set or the Japanese value set decreased utility by $0.09(\mathrm{p}=0.007)$. Respondents with TNM stage III or IV had a reduction in utility by $0.002(\mathrm{p}<0.001)$. For every one percent increase in proportion of patients having chemotherapy, radiotherapy and surgery, utility increased by $0.003,0.002$ and $0.001 \quad(\mathrm{p}<0.001)$ respectively. Mean utility for university educated is 0.81 and by including $\mathrm{Ou}$ (Taiwan) this increased by $0.15(\mathrm{p}=0.54)$, excluding Taiwan it dropped by 0.44 $(\mathrm{p}<0.001)$. Utility according to income is 0.78 utility and if income is less than 30,000 Yuan per year then utility rises by $0.17(\mathrm{p}<0.001)$. For married women, mean utility is 0.67 , adding Ou (Taiwan) increases this by $0.22(\mathrm{p}=0.43)$ and excluding it by $0.34(\mathrm{p}<0.001)$.

Extensive sensitivity analysis was undertaken and is shown in Table 11. The Li and Yang studies are most similar, both are conducted in China, use EQ5D5L and are valued with the China dataset, however the heterogeneity remains high at $85 \%$. Heterogeneity increases to $97 \%$ when adding the Wang study (also conducted in China, but uses the 3-level version of the EQ5D) or the Ou study (different study region, but same version of EQ5D5L and same value set). Heterogeneity increases to $98 \%$ when adding the Cheung study conducted in Singapore, and $99 \%$ when all studies are combined.

\section{Discussion}

We synthesised studies reporting health state utility values for Chinese women with breast cancer, for the purpose of parameterising a cost utility model. For all combinations of sensitivity analysis the range of utility values stayed between 0.82 when combining all five studies, to 0.87 when combining the two most closely related studies (Table 11). This 0.05 difference is less than the minimal clinically important difference reported by Pickard for all cancers (0.10 to 0.12 )[25]. As with all best 
Table 4 Summary of EQ5D utility scores included in studies

\begin{tabular}{|c|c|c|c|c|c|}
\hline Outcome & $\begin{array}{l}\text { Yang } 2020[20] \\
\mathrm{n}=446\end{array}$ & $\begin{array}{l}\text { Li } 2019 \text { [23] } \\
n=608\end{array}$ & $\begin{array}{l}\text { Ou } 2019[24] \\
n=193\end{array}$ & $\begin{array}{l}\text { Wang } 2018 \text { [22] } \\
n=2626\end{array}$ & $\begin{array}{l}\text { Cheung } 2014 \text { [21] } \\
n=238\end{array}$ \\
\hline EQ-5D-5L & Mean \pm SD & Mean \pm SD & Mean \pm SD & Mean $(95 \% \mathrm{Cl})$ & Mean \pm SD \\
\hline Mean & $0.86 \pm 0.19$ & $0.83 \pm 0.18$ & $0.92 \pm 0.09(n=182)$ & $0.78(0.77,0.79)$ & $0.77 \pm 0.163$ \\
\hline \multicolumn{6}{|l|}{ Stage or TNM stage } \\
\hline Stage/TNM 0 & $\mathrm{nr}$ & $\mathrm{nr}$ & $0.93 \pm 0.06(n=22)$ & $\mathrm{nr}$ & $\mathrm{nr}$ \\
\hline Stage/TNM I & $\mathrm{nr}$ & $\mathrm{nr}$ & $0.94 \pm 0.06(n=48)$ & $0.79(0.77,0.81)(n=498)$ & $\mathrm{nr}$ \\
\hline Stage/TNM 0\&l & $\mathrm{nr}$ & $0.83 \pm 0.17(n=175)$ & $\mathrm{nr}$ & $\mathrm{nr}$ & $\mathrm{nr}$ \\
\hline Stage/TNM II & $\mathrm{nr}$ & $0.86 \pm 0.18(n=142)$ & $0.91 \pm 0.10(n=65)$ & $0.79(0.78,0.80)(n=1,234)$ & $\mathrm{nr}$ \\
\hline Stage/TNM III & $\mathrm{nr}$ & $0.82 \pm 0.18(n=218)$ & $0.91 \pm 0.12(n=37)$ & $0.77(0.76,0.79)(n=556)$ & $\mathrm{nr}$ \\
\hline Stage/TNM IV & $\mathrm{nr}$ & $0.78 \pm 0.22(n=73)$ & $0.91 \pm 0.03(n=3)$ & $0.69(0.65,0.72)(n=224)$ & $\mathrm{nr}$ \\
\hline \multicolumn{6}{|l|}{ State } \\
\hline State P & $0.81 \pm 0.23(n=125)$ & $0.86 \pm 0.17(n=157)$ & $\mathrm{nr}$ & $\mathrm{nr}$ & $\mathrm{nr}$ \\
\hline State S & $0.90 \pm 0.12(n=258)$ & $0.85 \pm 0.16(n=245)$ & $\mathrm{nr}$ & $\mathrm{nr}$ & $\mathrm{nr}$ \\
\hline State $R$ & $0.78 \pm 0.31(n=20)$ & $0.72 \pm 0.16(n=65)$ & $\mathrm{nr}$ & $\mathrm{nr}$ & $\mathrm{nr}$ \\
\hline State M & $0.74 \pm 0.27(n=43)$ & $0.79 \pm 0.23(n=141)$ & $\mathrm{nr}$ & $\mathrm{nr}$ & $\mathrm{nr}$ \\
\hline \multicolumn{6}{|l|}{ Time since diagnosis } \\
\hline$\leq 12$ months & $0.81(n r)(n=133)$ & $0.81 \pm 0.18(n=190)$ & $\mathrm{nr}$ & $\mathrm{nr}$ & $\mathrm{nr}$ \\
\hline $13-36$ months & $0.89(n r)(n=147)$ & $0.84 \pm 0.18(n=197)$ & $0.92 \pm 0.08(n=66)^{a}$ & $\mathrm{nr}$ & $\mathrm{nr}$ \\
\hline $37-60$ months & $0.91(n r)(n=78)$ & $0.85 \pm 0.20(n=112)$ & $0.92 \pm 0.09(n=74) b$ & $\mathrm{nr}$ & $\mathrm{nr}$ \\
\hline$\geq 61$ months & $0.83(n r)(n=88)$ & $0.81 \pm 0.17(n=109)$ & $\begin{array}{l}0.94 \pm 0.10(n=27) c \\
0.89 \pm 0.10(n=25) d\end{array}$ & $\mathrm{nr}$ & $\mathrm{nr}$ \\
\hline \multicolumn{6}{|l|}{ Treatment regimen } \\
\hline Chemotherapy & $\mathrm{nr}$ & $0.86 \pm 0.17(n=288)$ & $0.91 \pm 0.10(n=135)$ & $0.80(0.78,0.81) \quad(n=689)$ & $\mathrm{nr}$ \\
\hline Surgery \& chemotherapy & $\mathrm{nr}$ & $0.71 \pm 0.15(n=69)$ & $\mathrm{nr}$ & $\begin{array}{ll}0.79(0.78,0.80) & (n=849) e \\
0.78(0.75,0.81) & (n=179) f\end{array}$ & $\mathrm{nr}$ \\
\hline Concurrent chemoradiotherapy & $\mathrm{nr}$ & $0.65 \pm 0.14(n=26)$ & $\mathrm{nr}$ & $0.76(0.70,0.82) \quad(n=47)$ & $\mathrm{nr}$ \\
\hline Radiotherapy & $\mathrm{nr}$ & $0.79 \pm 0.11(n=14)$ & $\begin{array}{l}0.94 \pm 0.08(n=71) g \\
0.91 \pm 0.10(n=108) h\end{array}$ & $\mathrm{nr}$ & $\mathrm{nr}$ \\
\hline Endocrine therapy & $0.88(n r)(n=307)$ & $0.86 \pm 0.16(n=73)$ & $\begin{array}{l}0.93 \pm 0.08(n=107) i \\
0.91 \pm 0.10(n=79) j\end{array}$ & $\mathrm{nr}$ & $\mathrm{nr}$ \\
\hline
\end{tabular}

TNM = Tumor, Nodes, Metastases. $\mathrm{nr}=$ not reported. a reported as $<36$ months; b reported as 3-6 years; $\mathrm{c}$ reported as $7-9$ years; $d$ reported as $>9$ years; e surgery and postoperative chemotherapy, f surgery \& neoadjuvant chemotherapy; $g$ partial mastectomy; h total mastectomy; i Tamoxifen, $j$ Aromatose inhibitors.

Table 5 Summary of single arm meta-analyses of studies of all breast cancer patients

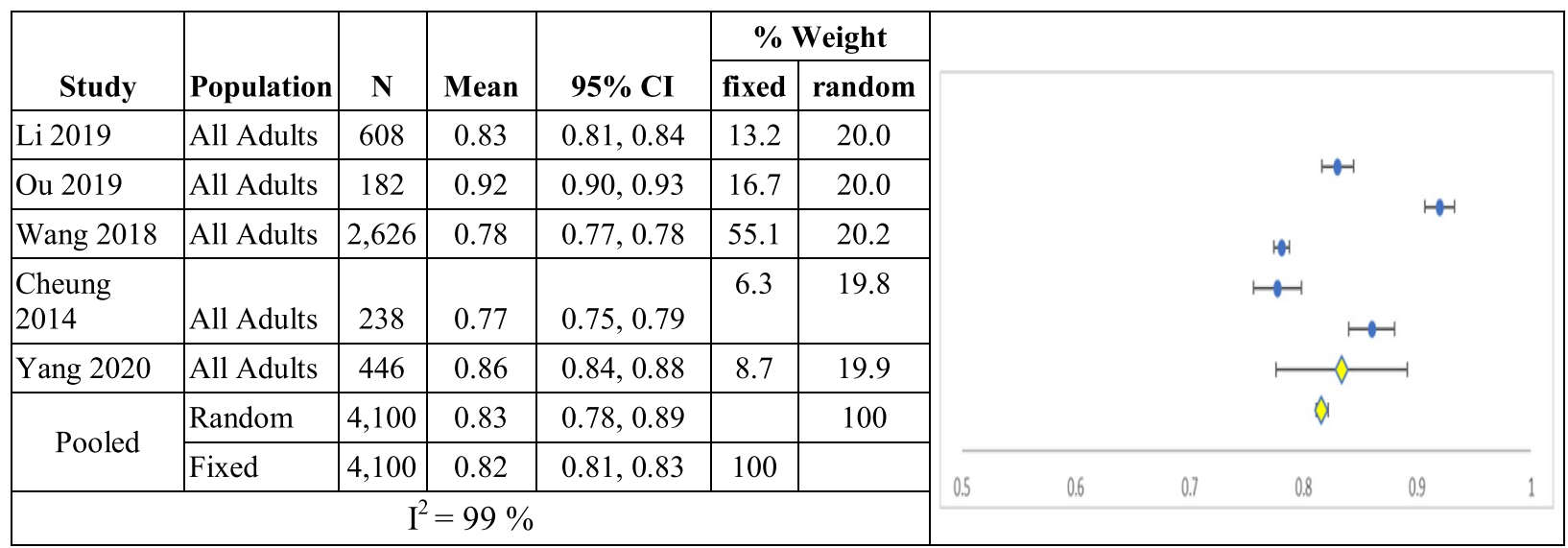

$\mathrm{Cl}=$ confidence interval 
Table 6 Summary of single arm meta-analyses of studies of breast cancer patients by TNM classification.

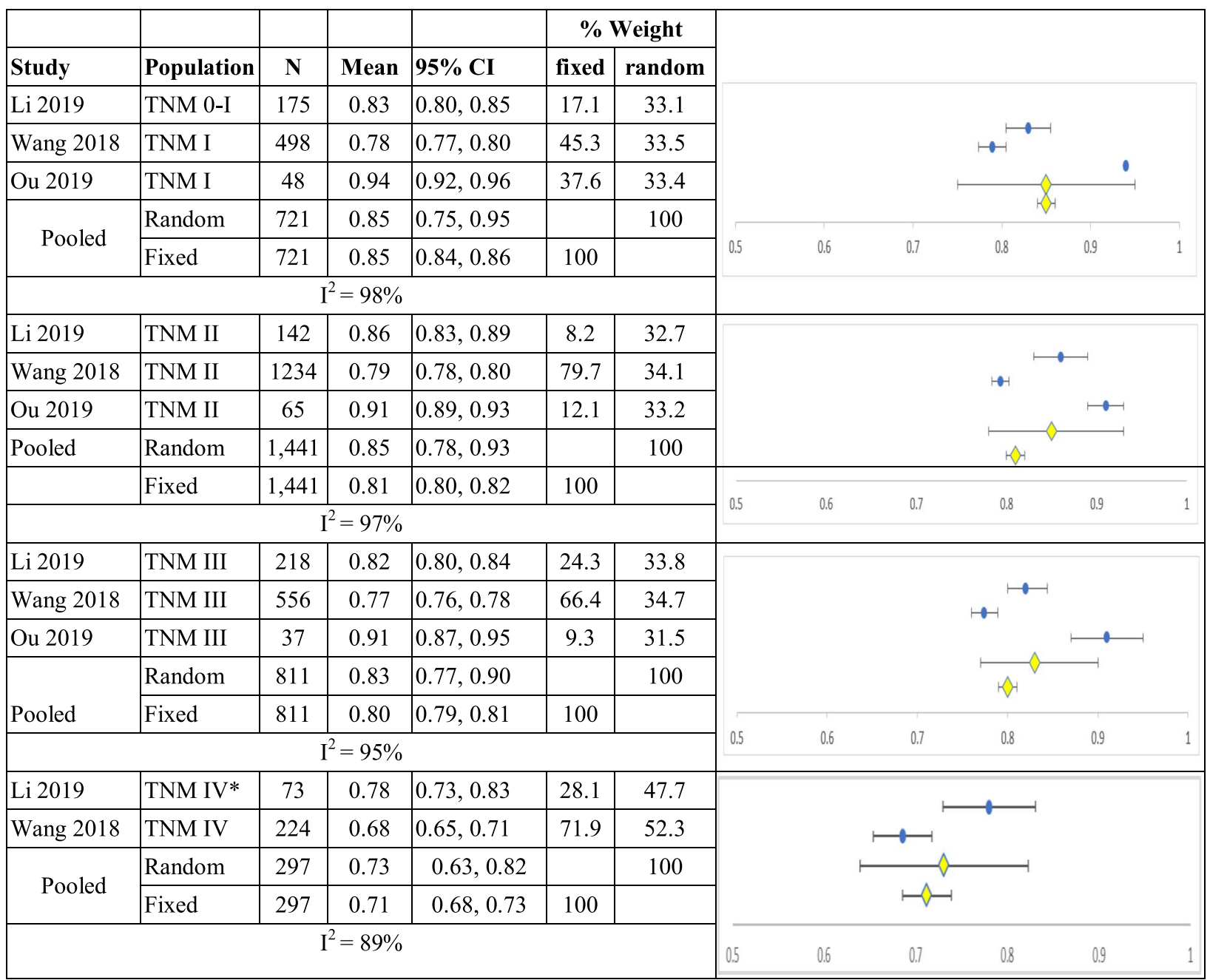

*Ou study included only 3 respondents therefore was excluded from this analysis, $\mathrm{Cl}=$ confidence interval; $\mathrm{TNM}=$ classification of malignant tumours ( $\mathrm{T}=$ size of tumor, $\mathrm{N}=$ spread to lymph nodes, $\mathrm{M}=$ metastasis)

practice in modelling, the uncertainty around the estimates produced in this meta-analysis should be explored in a probabilistic sensitivity analysis when incorporated into a cost utility model. As can be expected, the health state utility values for breast cancer patients overall (0.84) is lower than the general population in China (0.91 SD 0.18) [26]. Comparing the breast cancer stages, the random effects model utility for TNM 0, I and II was higher (0.85) than for TNM III (0.83) and TNM IV (0.73). However, the utility ranking did not match the severity of states (State $\mathrm{P}=0.84$, State $\mathrm{S}=0.88$, State $\mathrm{R}=0.73$, State $\mathrm{M}=0.78$ ).

Our study has a number of strengths, firstly it is based on a systematic and transparent literature search strategy designed to have high specificity to identify utility elicited by EQ-5D. Previous work has highlighted the need for strict inclusion criteria to minimise heterogeneity and cautions against pooling utilities derived from different instruments [27, 28]. In keeping with this, we restricted our study to EQ5D alone, therefore results are highly valid for cost utility analyses requiring utility for women with different stages of breast cancer in China. The quality of the studies has been assessed and is considered suitable for pooling the data. Another strength is that four of the five studies use value sets derived from China population. Literature has highlighted between region difference in value sets and noted the importance of using the region specific value set [27]. This is especially apparent in the case of Cheung, which reports the lowest mean utility 
Table 7 Summary of single arm meta-analyses of studies of breast cancer patients by PSRM State

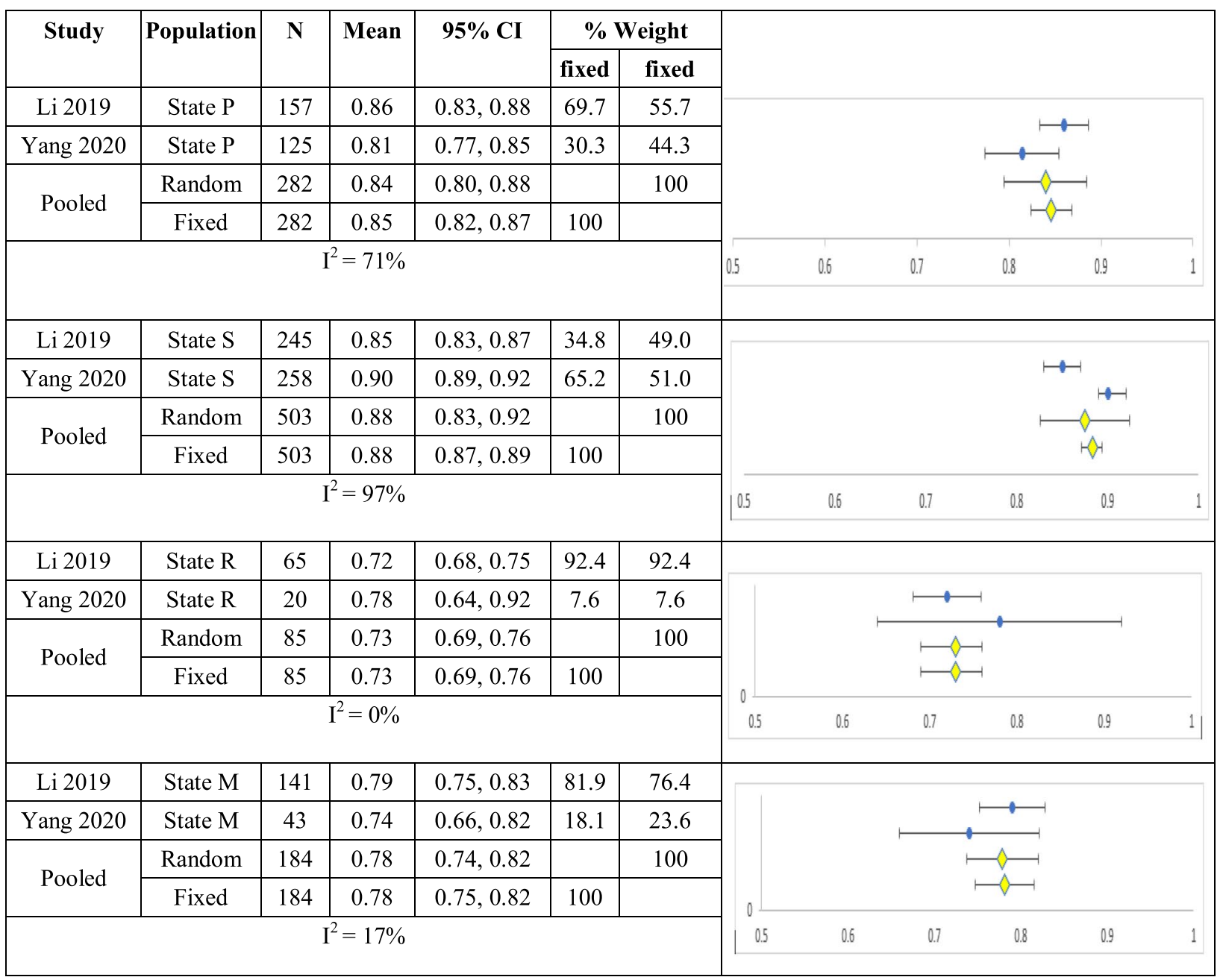

$\mathrm{Cl}$ - confidence interval; State $\mathrm{P}$, first year after primary breast cancer; State R, first year after recurrence; State $\mathrm{S}$, second and following years after primary breast cancer/recurrence; State M, metastatic breast cancer.

for women based on the Japanese value set. Comparing the value sets for China versus (vs.) Japan, the adjusted weighted average utility is higher for China ( 0.87 vs. 0.78 for 11112 ; 0.86 vs. 0.77 for $21111 ; 0.50$ vs. 0.49 for 22222 ; 0.51 vs. 0.29 for 32211 ; -0.14 vs. -0.13 for 33333 ) $[6,29]$. Therefore, including Cheung likely underestimates the utility of the general population in China. Ou is the outlier for region (Taiwan) and has the highest mean utility. Ou previously noted that the utility values were higher for Taiwan versus China. In addition, $\mathrm{Ou}$ includes only hormone receptor positive and human epidermal growth factor receptor 2 negative subtypes. When only the three China studies are included ( $\mathrm{Li}$, Yang, Wang) for random effects model the point estimate drops from 0.84 to 0.82 and the lower bound widens slightly from $(0.81,0.87)$ to $(0.77,0.87)$.
The research should be interpreted along with it's limitations. The first limitation is the high heterogeneity which is not uncommon with meta-analysis of EQ-5D and has been highlighted in the literature [16, 27, 30-32]. The interpretation of $\mathrm{I}^{2}$ is not well defined, as a guide, less than $40 \%$ may not be important; $30-60 \%$ indicates moderate heterogeneity, 50-90 indicates substantial heterogeneity and $75-100 \%$ considerable heterogeneity [33, 34]. Higgins has presented the case that "in relation to study effect sizes any amount of heterogeneity is acceptable, providing both that the predefined eligibility criteria for the metanalysis are sound and that the data are correct" [33]. Heterogeneity has been broadly described as clinical (variability in the participants, interventions, and outcomes) and methodological (study design, bias )[35]. In our study the methodological heterogeneity is welldefined and relates to the study region (China vs. Taiwan 
Table 8 Summary of single arm meta-analyses of studies of breast cancer patients by duration since diagnosis

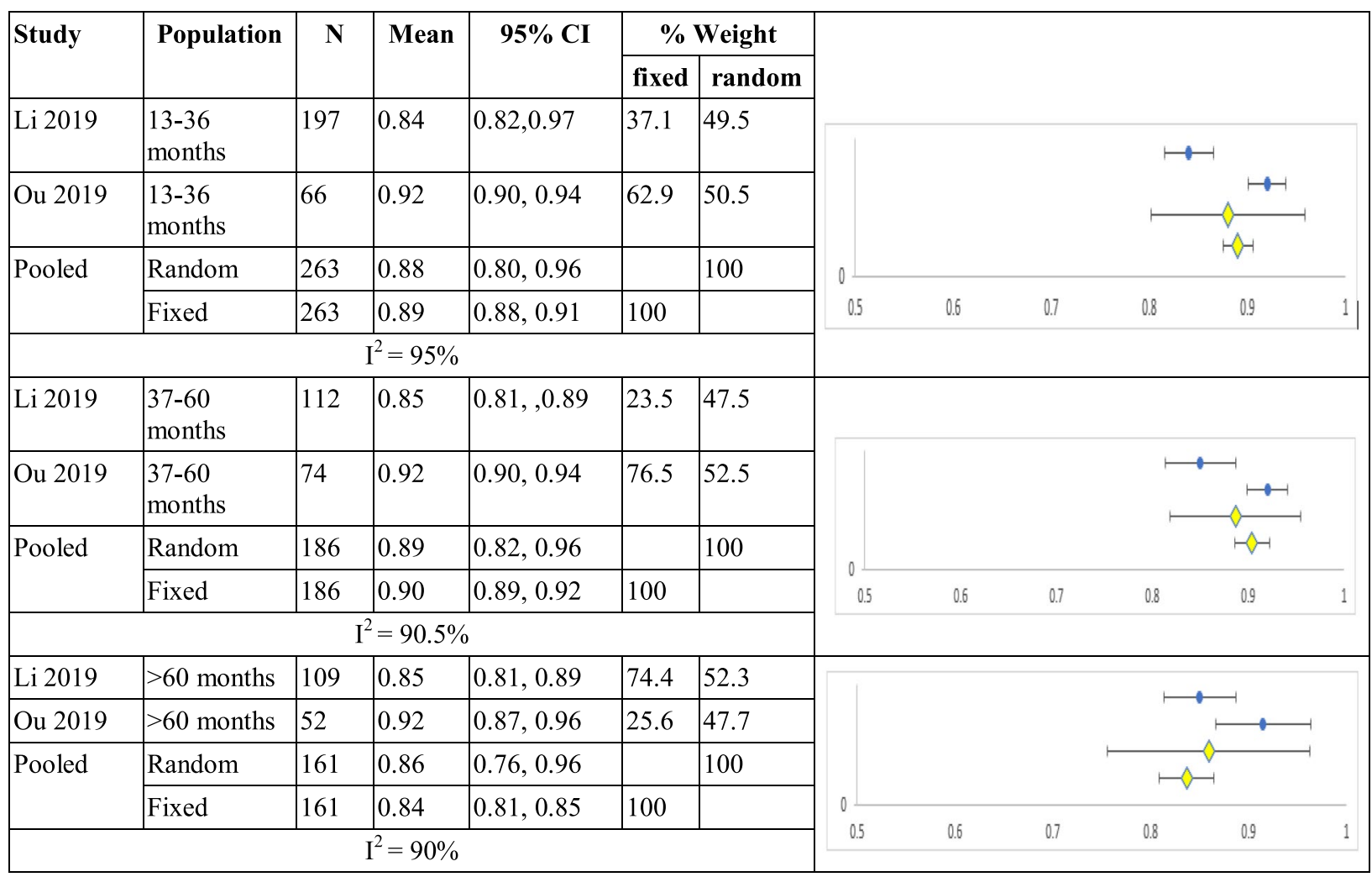

vs. Singapore), EQ-5D version (5L vs. 3L) and index value sets (EQ5D5L vs. EQ5D3L vs. Japanese). This explained heterogeneity is quantified in the meta-regression.

The clinical heterogeneity is more difficult to disentangle and contributes to the unexplained heterogeneity in our study. Synthesising the studies according to TNM status reduces the heterogeneity, although it remains considerable. Similarly, synthesising studies according to PSRM status further reduces heterogeneity notably to zero for State R. We believe this reflects the mix of treatments in the individual studies. For example the studies reported a range of treatments which are difficult to compare across studies because they reported different treatment combination, some of which are overlapping (not mutually exclusive) (see supplement). Chemotherapy for example has been identified as associated with poor quality of life $(\mathrm{Ou})$. The study with the lowest proportion of patients having chemotherapy (alone) was Wang (up to 30\%); Yang (up to 31\%); $\mathrm{Li}(47 \%)$; Cheung (50\%) and $\mathrm{Ou}(70 \%)$, (we note that these proportions of chemotherapy do not correspond to poorer quality of life values and further research is required to understand this relationship). Other studies have noted that chemotherapy is associated with poorer quality of life $(\mathrm{Ou})$. Not only are different treatment combinations provided, but the treatment setting also varies, for example in the Li study, $100 \%$ were inpatients compared to $29 \%$ in Cheung and $16 \%$ in Yang. Inpatient/outpatient mix is not reported for $\mathrm{Ou}$ and Wang. We can hypothesise that inpatients are "sicker" than outpatients and hence have lower utility. Another source of variability that it is not possible to explore in our analysis is the breast cancer subtypes. Ou included $100 \%$ patients with breast cancer subtypes HR-positive/ HER2-negative; (see supplement); Li included 54\% with ER/PR positive; Yang includes $80 \%$ HER positive patients. Chueng and Wang do not report the breast cancer subtypes. Literature suggests that patients have slightly different prognosis and outcomes than other breast cancer subtypes such as Luminal A and B. The subtypes are not provided for all studies and it was not possible to explore this variable for heterogeneity. The remaining heterogeneity likely reflects the diversity in duration since diagnosis (see supplement). The random effects model is likely to better account for the heterogeneity, however we wanted to present both sets of results so that the reader 
Table 9 Summary of single arm meta-analyses of studies of breast cancer patients by treatment regimen

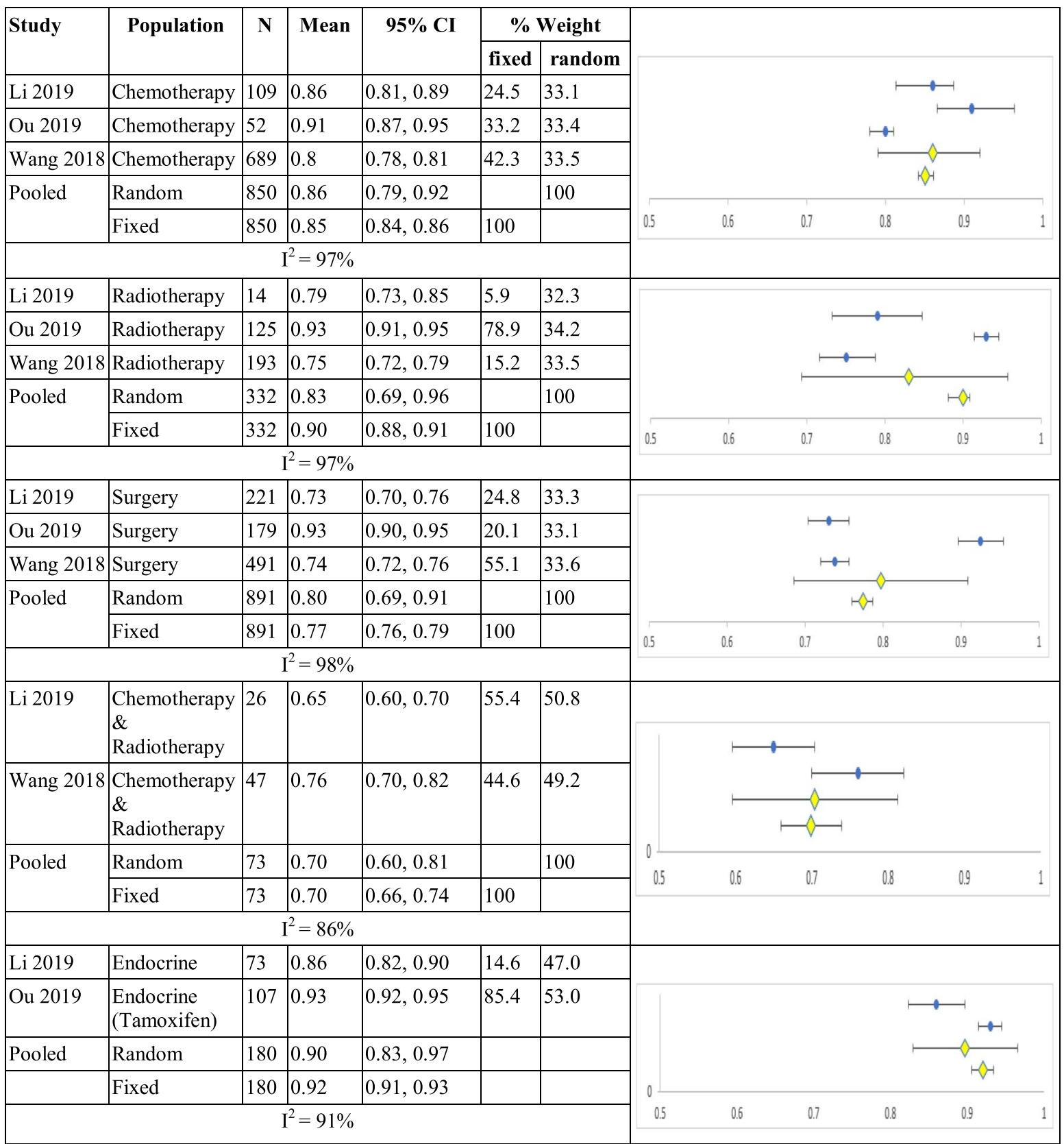

can see that there is not a large difference between the model estimates.

It is important to emphasise that in spite of the heterogeneity, the mean values do not vary greatly. A further limitation of our study is that the individual studies report mean and standard deviation, assuming normal distribution for their own analyses and the same assumption has been made for our analysis, however the ceiling effect of utility is well documented.
The reader should be aware that utility measured with instruments other than EQ5D will likely give different results [36].

To the best of our knowledge there is no other meta-analysis of EQ-5D utility values specific to Chinese patients with breast cancer. Peasgood et al performed a meta-analysis of health-related quality of life in breast cancer patients more broadly, including all countries and all empirical health-related quality of 
Table 10 Meta-regression of covariates for studies presenting summary data for all patients with breast cancer

\begin{tabular}{|c|c|c|c|c|c|}
\hline Covariate & Level & Coefficient & $95 \% \mathrm{Cl}$ & $P$ value & Studies \\
\hline \multirow[t]{3}{*}{ Region } & ${ }^{*}$ China & 0.82 & $0.79,0.85$ & & Li Wang Yang \\
\hline & Singapore & -0.05 & $0.11,0.02$ & 0.141 & Cheung \\
\hline & Taiwan & 0.10 & $0.04,0.16$ & $<0.001$ & $\mathrm{Ou}$ \\
\hline \multirow[t]{2}{*}{ Version of EQ5D } & EQ-5D-5L & 0.85 & $0.80,0.89$ & $<0.001$ & Li Yang Cheung Ou \\
\hline & EQ-5D-3L & -0.07 & $-0.17,0.03$ & 0.193 & Wang \\
\hline \multirow[t]{3}{*}{ Value set } & Chinese 5L & 0.87 & $0.84,0.90$ & $<0.001$ & LiYang Ou \\
\hline & Chinese $3 \mathrm{~L}$ & -0.09 & $-0.15,-0.02$ & 0.007 & Wang \\
\hline & Japanese & -0.09 & $-0.16,-0.03$ & 0.007 & Cheung \\
\hline \multirow[t]{2}{*}{ TNM } & Intercept & 0.93 & 0.739 & & Li Wang Yang Ou \\
\hline & Stage III or IV & -0.002 & $-0.008,0.003$ & 0.392 & Li Wang Yang Ou \\
\hline \multirow[t]{2}{*}{ Chemotherapy } & Intercept & 0.70 & $0.68,0.72$ & & LiWang Ou \\
\hline & Prop of pts receiving Chemo & 0.003 & $0.003,0.004$ & $<0.001$ & LiWang Ou \\
\hline \multirow[t]{2}{*}{ Radiotherapy } & Intercept & 0.80 & $0.76,0.83$ & & LiWang Ou \\
\hline & Prop of pts receiving Radio & 0.002 & $0.001,0.003$ & $<0.001$ & Li Wang Ou \\
\hline \multirow[t]{2}{*}{ Surgery } & Intercept & 0.79 & $0.75,0.84$ & & LiWang Ou \\
\hline & Prop of pts receiving Surgery & 0.001 & $0.00,0.002$ & $<0.001$ & LiWang Ou \\
\hline \multirow[t]{3}{*}{ University } & Intercept & 0.81 & $0.66,0.95$ & & \\
\hline & Including Taiwan & 0.15 & $-0.33,0.62$ & 0.54 & Li Yang Ou Cheung \\
\hline & Excluding Taiwan & -0.44 & $-0.59,-0.28$ & $<0.001$ & Li Yang Cheung \\
\hline \multirow[t]{2}{*}{ Income } & Intercept & 0.78 & $0.76,0.80$ & & LiYang Ou \\
\hline & $<30,000$ Yuan / yr & 0.17 & $0.09,0.24$ & $<0.001$ & LiYang Ou \\
\hline \multirow[t]{3}{*}{ Married } & Intercept & 0.67 & $0.21,1.0$ & & Li Yang Ou Cheung \\
\hline & Including Taiwan & 0.22 & $-0.32,0.76$ & 0.43 & Li Yang Ou Cheung \\
\hline & Excluding Taiwan & 0.34 & $0.23,0.46$ & $<0.001$ & LiYang Cheung \\
\hline
\end{tabular}

*reference group

Table 11 Sensitivity analysis, selective analysis for the five studies meeting the inclusion criteria

\begin{tabular}{|c|c|c|c|c|c|c|c|c|c|c|}
\hline & Studies & Measure & Region & Value set & $\mathrm{N}$ & Mean & $95 \% \mathrm{Cl}$ & Weight (\%) & Estimate $[95 \% \mathrm{Cl}]$ & $I^{2}(\%)$ \\
\hline \multirow[t]{3}{*}{1} & \multicolumn{10}{|c|}{ Studies conducted in China, using EQ5D5L, valued by same China dataset (Luo 2017) } \\
\hline & Li 2019 & EQ-5D-5L & China & China EQ5D5L, Luo 2017 & 608 & 0.83 & $0.81,0.84$ & 51 & \multirow{2}{*}{$\begin{array}{l}0.84 \\
{[0.81,0.87]}\end{array}$} & \multirow[t]{2}{*}{85} \\
\hline & Yang 2020 & EQ-5D-5L & China & China EQ5D5L, Luo 2017 & 446 & 0.86 & $0.84,0.87$ & 48 & & \\
\hline \multirow[t]{4}{*}{2} & \multicolumn{10}{|c|}{ Studies using EQ5D5L in China } \\
\hline & Li 2019 & EQ-5D-5L & China & China EQ5D5L, Luo 2017 & 608 & 0.83 & $0.81,0.84$ & 33 & \multirow{3}{*}{$\begin{array}{l}0.82 \\
{[0.77,0.87]}\end{array}$} & \multirow[t]{3}{*}{97} \\
\hline & Yang 2020 & EQ-5D-5L & China & China EQ5D5L, Luo 2017 & 446 & 0.86 & $0.84,0.87$ & 32 & & \\
\hline & Wang 2018 & EQ-5D-3L & China & China EQ5D3L, Liu 2014 & 2626 & 0.78 & $0.77,0.78$ & 34 & & \\
\hline \multirow[t]{4}{*}{3} & \multicolumn{10}{|c|}{ Studies using EQ5D5L, valued by same China dataset (Luo 2017) } \\
\hline & Li 2019 & EQ-5D-5L & China & China EQ5D5L, Luo 2017 & 608 & 0.83 & $0.81,0.84$ & 33 & \multirow{3}{*}{$\begin{array}{l}0.87 \\
{[0.81,0.92]}\end{array}$} & \multirow[t]{3}{*}{97} \\
\hline & Yang 2020 & EQ-5D-5L & China & China EQ5D5L, Luo 2017 & 446 & 0.86 & $0.84,0.87$ & 33 & & \\
\hline & Ou 2019 & EQ-5D-5L & Taiwan & China EQ5D5L, Luo 2017 & 193 & 0.92 & $0.90,0.93$ & 33 & & \\
\hline \multirow[t]{5}{*}{4} & \multicolumn{10}{|c|}{ Studies using EQ5D5L } \\
\hline & Li 2019 & EQ-5D-5L & China & China EQ5D5L, Luo 2017 & 608 & 0.83 & $0.81,0.84$ & 25 & \multirow{4}{*}{$\begin{array}{l}0.84 \\
{[0.78,0.90]}\end{array}$} & \multirow[t]{4}{*}{98} \\
\hline & Yang 2020 & EQ-5D-5L & China & China EQ5D5L, Luo 2017 & 446 & 0.86 & $0.84,0.87$ & 24 & & \\
\hline & Ou 2019 & EQ-5D-5L & Taiwan & China EQ5D5L, Luo 2017 & 193 & 0.92 & $0.90,0.93$ & 25 & & \\
\hline & Cheung 2014 & EQ-5D-5L & Singapore & Japanese (Rabin) & 238 & 0.77 & $0.75,0.79$ & 24 & & \\
\hline \multirow[t]{6}{*}{5} & All studies & & & & & & & & & \\
\hline & Li 2019 & EQ-5D-5L & China & China EQ5D5L, Luo 2017 & 608 & 0.83 & $0.81,0.84$ & 20 & \multirow{5}{*}{$\begin{array}{l}0.83 \\
{[0.77,0.89]}\end{array}$} & \multirow[t]{5}{*}{99} \\
\hline & Yang 2020 & EQ-5D-5L & China & China EQ5D5L, Luo 2017 & 446 & 0.86 & $0.84,0.87$ & 19 & & \\
\hline & Ou 2019 & EQ-5D-5L & Taiwan & China EQ5D5L, Luo 2017 & 193 & 0.92 & $0.90,0.93$ & 20 & & \\
\hline & Cheung 2014 & EQ-5D-5L & Singapore & Japanese (Rabin) & 238 & 0.77 & $0.75,0.79$ & 19 & & \\
\hline & Wang 2018 & EQ-5D-3L & China & China EQ5D3L, Liu 2014 & 2626 & 0.78 & $0.77,0.78$ & 20 & & \\
\hline
\end{tabular}


life measuring instruments [37]. They identified 49 articles providing 476 utilities for breast cancer states including screening, prevention, adverse events, nonspecific breast cancer, early and metastatic breast cancer. Utility values were pooled using ordinary least squares regression. The range of utilities from our study (0.82 to 0.87 ) were higher for early-stage breast cancer compared to Peasgood's (0.66 to 0.78 ). The values for our study for TNM stages III and IV generally aligned with Peasgood's findings (0.83 TNM III and 0.73 TNM IV versus Peasgood's 0.72 and 0.80 for metastatic breast cancer). The Peasgood meta-analysis found that utility varied significantly according to valuation method [27]. There are no other other metaanalyses to our knowledge combining utility values for breast cancer.

\section{Conclusion}

This study provides a meta-analysis of health state utility values measured by EQ5D by patients identifying as Chinese with breast cancer which may be used to inform cost utility models.

\begin{abstract}
Abbreviations
AB: abstract; Cl: confidence interval; COVID-19: corona virus disease 19; DARE: Database of abstracts of reviews of effectiveness; EQ5D: EuroQol 5-dimensions; EQ-5D-3L: EuroQol 5-dimensions three level; EQ-5D-5L: EuroQol 5-dimensions five level; HTA: Health technology assessment; NHS EED: National health service economic evaluation; NOS: Newcastle ottawa scale; PSRM: State $P$, first year after primary breast cancer; State $R$, first year after recurrence; State $S$, second and following years after primary breast cancer/ recurrence; State $M$, metastatic breast cancer.; TI: title; TNM: Tumor Nodal Metastases; TTO: Time trade off; TW: Text word; PRISMA: Preferred Reporting Items for Systematic Reviews and Meta-Analyses.
\end{abstract}

\section{Supplementary Information}

The online version contains supplementary material available at https://doi. org/10.1186/s12885-021-09140-5.

Additional file 1.

\section{Authors' contributions}

MD, TR conceptualised the study, BH, UZ, TR completed the literature search and review, $\mathrm{BH}, \mathrm{TR}$ did the meta-analysis and meta-regression, MD, TR, BH, UZ reviewed and approved the manuscript. All authors have read and approved the manuscript

\section{Funding}

This research informs one parameter of a cost utility model funded by a pharmaceutical company, however the meta-analysis was undertaken independently as an academic exercise only and no direct funding was received for the meta-analysis described in this paper.

\section{Availability of data and materials}

All data generated or analysed during this study are included in this published article and its supplementary information files.

\section{Declarations}

Ethics approval and consent to participate

The study was not eligible for ethics approval because it was based on published literature.

\section{Consent for publication}

Not applicable.

\section{Competing interests}

The authors declare that they have no competing or conflict of interest.

\section{Author details}

${ }^{1}$ Centre for Applied Health Economics, Griffith University, Brisbane, Australia.

${ }^{2}$ Assessment in Medicine $\mathrm{GmbH}$, Berlin, Germany.

Received: 2 February 2021 Accepted: 22 December 2021

Published online: 10 January 2022

\section{References}

1. Sung H, et al. Global Cancer Statistics 2020: GLOBOCAN Estimates of Incidence and Mortality Worldwide for 36 Cancers in 185 Countries. CA Cancer J Clin. 2021;71(3):209-49.

2. Cao W, et al. Changing profiles of cancer burden worldwide and in China: a secondary analysis of the global cancer statistics 2020. Chin Med J (Engl). 2021:134(7):783-91.

3. Chen W, et al. Cancer statistics in China, 2015. CA Cancer J Clin. 2016:66(2):115-32.

4. Liu, G., China Guidelines for Pharmacoeconomic Evaluations 2020 Edition, ed. G. Liu. 2020, Beijing China.

5. China Guidelines for Pharmacoeconomic Evaluations 2011; Available from: ISPOR website.

6. Luo N, et al. Estimating an EQ-5D-5L Value Set for China. Value Health. 2017;20(4):662-9

7. Lee CF, et al. The English and Chinese versions of the five-level EuroQoL Group's five-dimension questionnaire (EQ-5D) were valid and reliable and provided comparable scores in Asian breast cancer patients. Support Care Cancer. 2013;21(1):201-9.

8. Kim S-H, et al. Validity and reliability of EQ-5D-3L for breast cancer patients in Korea. Health and Quality of Life Outcomes. 2015;13(1):203.

9. Kimman ML, et al. Responsiveness of the EQ-5D in breast cancer patients in their first year after treatment. Health and quality of life outcomes. 2009;7:11-1.

10. Saramago P, Manca A, Sutton AJ. Deriving input parameters for costeffectiveness modeling: taxonomy of data types and approaches to their statistical synthesis. Value Health. 2012;15(5):639-49.

11. Wells, G.S., B. O'Connell, D. Peterson, J. Welch, V. Losos, M. Tugwell, P. The Newcastle-Ottawa Scale (NOS) for assessing the quality of nonrandomised studies in meta-analyses. 2020 [cited 2020 26.12.2020]; Available from: http://www.ohri.ca/programs/clinical_epidemiology/oxford.asp.

12. Balk, E.M., et al., AHRQ Comparative Effectiveness Reviews, in Venous Thromboembolism Prophylaxis in Major Orthopedic Surgery: Systematic Review Update. 2017, Agency for Healthcare Research and Quality (US): Rockville (MD).

13. Cortegiani A, et al. Update I. A systematic review on the efficacy and safety of chloroquine/hydroxychloroquine for COVID-19. J Crit Care. 2020;59:176-90.

14. Moher D, et al. Preferred reporting items for systematic reviews and meta-analyses: the PRISMA statement. Bmj. 2009;339:b2535.

15. Moher $D$, et al. Preferred reporting items for systematic review and metaanalysis protocols (PRISMA-P) 2015 statement. Syst Rev. 2015;4(1):1.

16. Petrou S, Kwon J, Madan J. A Practical Guide to Conducting a Systematic Review and Meta-analysis of Health State Utility Values. Pharmacoeconomics. 2018:36(9):1043-61.

17. Schwarzer, G. Meta: an R package for meta-analysis. 2007 [cited 2020 27.12.2020]; Available from: https://cran.rstudio.org/doc/Rnews/Rnews_ 2007-3.pdf\#page $=40$. 
18. Higgins JP, et al. Measuring inconsistency in meta-analyses. Bmj. 2003:327(7414):557-60.

19. Yang Q, et al. Mapping function from FACT-B to EQ-5D-5 L using multiple modelling approaches: data from breast cancer patients in China. Health Qual Life Outcomes. 2019;17(1):153.

20. Yang $Q$, Yu X, Zhang W. Health variations among breast-cancer patients from different disease states: evidence from China. BMC Health Serv Res. 2020;20(1):1033.

21. Cheung YB, et al. Mapping the functional assessment of cancer therapybreast (FACT-B) to the 5-level EuroQoL Group's 5-dimension questionnaire (EQ-5D-5L) utility index in a multi-ethnic Asian population. Health Qual Life Outcomes. 2014;12:180.

22. Wang $L$, et al. Health-related quality of life and utility scores of patients with breast neoplasms in China: A multicenter cross-sectional survey. Breast. 2018;39:53-62.

23. Li S, et al. Which approach is better in eliciting health state utilities from breast cancer patients? Evidence from mainland China. Eur J Cancer Care (Engl). 2019;28(2):e12965.

24. Ou HT, et al. Health-related quality of life associated with different cancer treatments in Chinese breast cancer survivors in Taiwan. Eur J Cancer Care (Engl). 2019;28(4):e13069.

25. Pickard AS, Neary MP, Cella D. Estimation of minimally important differences in EQ-5D utility and VAS scores in cancer. Health Qual Life Outcomes. 2007:5:70.

26. Wang HM, et al. Validation of the EQ-5D in a general population sample in urban China. Qual Life Res. 2012;21 (1):155-60.

27. Peasgood T, Brazier J. Is Meta-Analysis for Utility Values Appropriate Given the Potential Impact Different Elicitation Methods Have on Values? Pharmacoeconomics. 2015;33(11):1101-5.

28. Sturza J. A review and meta-analysis of utility values for lung cancer. Med Decis Making. 2010;30(6):685-93.

29. Tsuchiya A, et al. Estimating an EQ-5D population value set: the case of Japan. Health Econ. 2002;11(4):341-53.

30. Peasgood T, et al. An updated systematic review of Health State Utility Values for osteoporosis related conditions. Osteoporos Int. 2009;20(6):853-68.

31. Doth $A H$, et al. The burden of neuropathic pain: a systematic review and meta-analysis of health utilities. Pain. 2010;149(2):338-44.

32. McLernon DJ, Dillon J, Donnan PT. Health-state utilities in liver disease: a systematic review. Med Decis Making. 2008;28(4):582-92.

33. Higgins JP. Commentary: Heterogeneity in meta-analysis should be expected and appropriately quantified. Int J Epidemiol. 2008;37(5):1158-60.

34. Patsopoulos NA, Evangelou E, loannidis JP. Sensitivity of between-study heterogeneity in meta-analysis: proposed metrics and empirical evaluation. Int J Epidemiol. 2008;37(5):1148-57.

35. Haidich AB. Meta-analysis in medical research. Hippokratia. 2010;14(Suppl 1):29-37.

36. Rautalin $\mathrm{M}$, et al. Health-related quality of life in different states of breast cancer - comparing different instruments. Acta Oncol. 2018;57(5):622-8.

37. Peasgood, T.W., S. Brazier, J. HEDS Discussion Paper 10/15. A review and meta-analysis of health state utility values in breast cancer. 2010 27.12.2020]; Available from: https://mpra.ub.uni-muenchen.de/29950/.

\section{Publisher's Note}

Springer Nature remains neutral with regard to jurisdictional claims in published maps and institutional affiliations.

Ready to submit your research? Choose BMC and benefit from:

- fast, convenient online submission

- thorough peer review by experienced researchers in your field

- rapid publication on acceptance

- support for research data, including large and complex data types

- gold Open Access which fosters wider collaboration and increased citations

- maximum visibility for your research: over $100 \mathrm{M}$ website views per year

At BMC, research is always in progress.

Learn more biomedcentral.com/submissions 